Check for updates

Cite this: RSC Adv., 2018, 8, 13054

Received 27th January 2018

Accepted 26th March 2018

DOI: $10.1039 / c 8 r a 00844 b$

rsc.li/rsc-advances

\section{Synthesis, electronic structures, and photoluminescence properties of an efficient and thermally stable red-emitting phosphor $\mathrm{Ca}_{3} \mathrm{ZrSi}_{2} \mathrm{O}_{9}: \mathrm{Eu}^{3+}{ }_{,} \mathrm{Bi}^{3+}$ for deep UV-LEDs}

\author{
Jiyou Zhong, (D) a Weiren Zhao, ${ }^{\text {*a }}$ Lunwei Yang, ${ }^{\mathrm{b}}$ Peng Shi, ${ }^{a}$ Zifeng Liao, ${ }^{\mathrm{a}}$ \\ Menglong Xia, ${ }^{a}$ Wenhua $\mathrm{Pu}^{\mathrm{b}}$ Wei Xiao ${ }^{\mathrm{b}}$ and Ligen Wang ${ }^{\star b}$
}

A series of red-emitting $\mathrm{Ca}_{3} \mathrm{ZrSi}_{2} \mathrm{O}_{9}: \mathrm{Eu}^{3+}, \mathrm{Bi}^{3+}$ phosphors was synthesized using a conventional high temperature solid-state reaction method, for the purpose of promoting the emission efficiency of $\mathrm{Eu}^{3+}$ in a $\mathrm{Ca}_{3} \mathrm{ZrSi}_{2} \mathrm{O}_{9}$ host. The site preference of $\mathrm{Bi}^{3+}$ and $\mathrm{Eu}^{3+}$ in the $\mathrm{Ca}_{3} \mathrm{ZrSi}_{2} \mathrm{O}_{9}$ host was evaluated by formation energy. The effects of $\mathrm{Bi}^{3+}$ on electronic structure, luminescent properties, and related mechanisms were investigated. The inner quantum yield of the optimized sample increased to $72.9 \%(x$ $=0.08)$ from $34.6 \%(x=0)$ at $300 \mathrm{~nm}$ ultraviolet light excitation. The optimized sample $(x=0.08)$ also showed excellent thermal stability, and typically, $84.2 \%$ of the initial emission intensity was maintained when the temperature increased to $150{ }^{\circ} \mathrm{C}$ from $25{ }^{\circ} \mathrm{C}$, which is much higher than that without $\mathrm{Bi}^{3+}$ doping (70.1\%). The mechanisms of emission properties and thermal stability enhancement, as well as the redshift of the charge transfer band (CTB) induced by $\mathrm{Bi}^{3+}$ doping in the $\mathrm{Ca}_{3} \mathrm{ZrSi}_{2} \mathrm{O}_{9}: \mathrm{Eu}^{3+}$ phosphor, were discussed. This study elucidates the photoluminescence properties of $\mathrm{Bi}^{3+}$-doped $\mathrm{Ca}_{3} \mathrm{ZrSi}_{2} \mathrm{O}_{9}: \mathrm{Eu}^{3+}$ phosphor, and indicates that it is a promising luminescent material that can be used in ultraviolet lightemitting diodes.

\section{Introduction}

Phosphor-converted white light-emitting diodes (pc-WLEDs) have the advantages of long lifetime, high luminous efficacy, and environmental friendliness, and are becoming an indispensable solid-state light source in our daily life. ${ }^{1-5}$ However, conventional WLEDs using blue InGaN chips combined with phosphors are very likely to cause health problems because excessive exposure to monochromatic blue light often results from their use. ${ }^{6,7}$ Therefore, ultraviolet (UV) LEDs combined with phosphors are an important and promising alternative for the fabrication of full spectrum lighting sources that are healthy and comfortable to human beings. ${ }^{8,9}$ With their rapid development, UV LEDs are mainly divided into near-UV LEDs (300-400 $\mathrm{nm}$ ) and deep UV LEDs (200-300 nm). ${ }^{10}$ Correspondingly, new highly efficient and thermally stable phosphors should be rapidly developed so as to match the emission wavelength of UV LED chips. ${ }^{11}$ Generally, $\mathrm{Y}_{2} \mathrm{O}_{3}: \mathrm{Eu}^{3+}$ is considered a red-emitting phosphor for UV LEDs that are solely composed of rare earth elements. Because rare earth elements are non-renewable

${ }^{a}$ School of Physics and Optoelectronic Engineering, Guangdong University of Technology, Guangzhou 510006, China.E-mail: zwren123@126.com

${ }^{b}$ Center for Computing and Simulation of Advanced Materials, State Key Laboratory of Nonferrous Metals and Processes, General Research Institute for Nonferrous Metals, Beijing 100088, China. E-mail: lg_wang1@yahoo.com resources, it is necessary to develop efficient and thermally stable red-emitting phosphors with inexpensive raw materials and comparative properties to replace the use of $\mathrm{Y}_{2} \mathrm{O}_{3}: \mathrm{Eu}^{3+}$ in UV LEDs.

Recently, Kim et al. reported a cuspidine-type $\mathrm{Ca}_{3} \mathrm{ZrSi}_{2} \mathrm{O}_{9}$ :$\mathrm{Eu}^{3+}$ red-emitting phosphor possessing a relative emission intensity that reached $84 \%$ of commercial red-emitting $\mathrm{Y}_{1.94} \mathrm{Eu}_{0.06} \mathrm{O}_{3}$ phosphors, and it seemed promising as a replacement for $\mathrm{Y}_{2} \mathrm{O}_{3}: \mathrm{Eu}^{3+}$, but the inner quantum yield was only $41 \%$ at $268 \mathrm{~nm}$ excitation. ${ }^{\mathbf{1 2}}$ In order to further enhance the emission efficiency, Zuo et al. tried to partially substitute $\mathrm{Zr}^{4+}$ ions with $\mathrm{Al}^{3+}$ ions in the host $\mathrm{Ca}_{3} \mathrm{ZrSi}_{2} \mathrm{O}_{9}$, and finally the inner quantum yield was increased to $46 \%{ }^{13}$ This enhancement was mainly ascribed to the charge compensation effect, which is helpful for improving the crystallinity of the phosphors. However, the relatively low quantum yield still limits its practical use.

Here, we report another route for enhancing the quantum yield of this phosphor by introducing the sensitizer $\mathrm{Bi}^{3+}$ into the lattice. It is known that $\mathrm{Bi}^{3+}$ has an $\mathrm{ns}^{2}$-type ground state electric configuration $\left({ }^{1} \mathrm{~S}_{0}\right.$ state) and ${ }^{1} \mathrm{~S}_{0} \rightarrow{ }^{3} \mathrm{P}_{1}$ and ${ }^{1} \mathrm{~S}_{0} \rightarrow{ }^{1} \mathrm{P}_{1}$ spinallowed transitions, which are expected to have a reasonable absorption strength. ${ }^{14}$ The aborted energy can be efficiently transferred to luminescence center ions, such as $\mathrm{Eu}^{3+}$ and $\mathrm{Mn}^{4+}$, which act as a sensitizer, or directly emitting photons, acting as a luminescence center due to the transitions of ${ }^{3} \mathrm{P}_{1} \rightarrow{ }^{1} \mathrm{~S}_{0}$ and 
${ }^{1} \mathrm{P}_{1} \rightarrow{ }^{1} \mathrm{~S}_{0} \cdot{ }^{15-19}$ For this reason, many commercially available $\mathrm{Eu}^{3+}$-activated phosphors, such as $\mathrm{Y}_{2} \mathrm{O}_{3}: \mathrm{Eu}^{3+}$ and $\mathrm{Y}(\mathrm{P}, \mathrm{V}) \mathrm{O}_{4}: \mathrm{Eu}^{3+}$, adopt $\mathrm{Bi}^{3+}$ as sensitizer. ${ }^{20-22}$ In this approach, the inner quantum yield of $\mathrm{Ca}_{3} \mathrm{ZrSi}_{2} \mathrm{O}_{9}: \mathrm{Eu}^{3+}, \mathrm{Bi}^{3+}$ was greatly promoted, and the thermal stability was also enhanced. To further understand this enhancement, first principles calculations were performed to investigate the site preference of dopants and electronic structure variations induced by $\mathrm{Bi}^{3+}$ doping. The synthesis and photoluminescence properties were also experimentally characterized in detail. The photoluminescence investigation demonstrates that the $\mathrm{Ca}_{3} \mathrm{ZrSi}_{2} \mathrm{O}_{9}: \mathrm{Eu}^{3+}, \mathrm{Bi}^{3+}$ phosphor is a promising red-emitting phosphor that can be incorporated into UV LEDs.

\section{Methodology}

\subsection{Experimental details}

The samples with formula $\left(\mathrm{Ca}_{2.83-x} \mathrm{Eu}_{0.17} \mathrm{Bi}_{x}\right) \mathrm{ZrSi}_{2} \mathrm{O}_{9}(x=0-$ $0.16)$ were synthesized by the high-temperature solid-state reaction method. The starting materials consisting of $\mathrm{CaCO}_{3}$ (Aldrich, 99.95\%), $\mathrm{Bi}_{2} \mathrm{O}_{3}$ (Aldrich, 99.9\%), $\mathrm{ZrO}_{2}$ (Aldrich, 99.5\%), $\mathrm{SiO}_{2}$ (Aldrich, 99.99\%) and $\mathrm{Eu}_{2} \mathrm{O}_{3}$ (Aldrich, 99.95\%) were weighed according to the stoichiometric ratio. The mixed powder was evenly ground in an agate mortar, and then the homogeneous mixtures were placed in an alumina crucible and continually heated at $1400{ }^{\circ} \mathrm{C}$ in an air atmosphere for $6 \mathrm{~h}$. The samples were gradually cooled to room temperature and then ground once more until a fine powder was obtained.

The powder X-ray diffraction (XRD) patterns were measured using an X-ray powder diffractometer (Rigaku, Japan) with $\mathrm{Cu}$ $\mathrm{K} \alpha$ radiation $(\lambda=1.5406 \AA)$. The photoluminescence spectra and the decay curves of $\mathrm{Eu}^{3+}$ lifetime values were measured using a FLS-980 fluorescence spectrophotometer (Edinburgh Instruments) equipped with a xenon lamp (450 W, Osram) as the excitation source. The quantum yield and temperaturedependent emission spectra were measured using the QE2100 quantum yield measurement system (Otsuka Electronics Co., Ltd., Japan), composed of an integrating sphere, a heating apparatus, and a Xe lamp used as an excitation source and white $\mathrm{BaSO}_{4}$ powder as a reference.

\subsection{Computational details}

Structural optimization of $\mathrm{Ca}_{3} \mathrm{ZrSi}_{2} \mathrm{O}_{9}, \mathrm{Ca}_{3} \mathrm{ZrSi}_{2} \mathrm{O}_{9}: \mathrm{Bi}^{3+}$, and $\mathrm{Ca}_{3} \mathrm{ZrSi}_{2} \mathrm{O}_{9}: \mathrm{Eu}^{3+}$ was firstly performed using the density functional theory (DFT) method with the Perdew-Burke-Ernzerhof (PBE) exchange-correlation functional, ${ }^{23}$ as implemented in the VASP software package. ${ }^{24,25}$ The electronic properties of $\mathrm{Ca}_{3}$ $\mathrm{ZrSi}_{2} \mathrm{O}_{9}: \mathrm{Bi}^{3+}$ were then calculated based on the optimized geometries using the hybrid PBE functional. The $\mathrm{Ca}_{3} \mathrm{ZrSi}_{2} \mathrm{O}_{9}$ host crystal containing 60 atoms was used as the computational model. The Ca $3 \mathrm{~s}^{2} 3 \mathrm{p}^{6} 4 \mathrm{~s}^{2}$, Zr $4 \mathrm{~s}^{2} 4 \mathrm{p}^{6} 5 \mathrm{~s}^{2} 4 \mathrm{~d}^{2}$, Si $3 \mathrm{~s}^{2} 3 \mathrm{p}^{2}$, O $2 \mathrm{~s}^{2} 2 \mathrm{p}^{4}$, Bi $5 d^{10} 6 s^{2} 6 p^{3}$, and Eu $5 s^{2} 5 p^{6} 4 f^{6} 5 d^{1} 6 s^{2}$ electrons were treated as the valence electrons, whose interactions with the ion cores were treated with the projected augmented wave (PAW) method. ${ }^{26}$ The geometric structures were fully relaxed with the convergence criteria of $10^{-6} \mathrm{eV}$ used for the change in the total energy and $0.01 \mathrm{eV} \AA^{-1}$ used for Hellmann-Feynman forces on atoms. The cut-off energy of $550 \mathrm{eV}$ was used for the basis set of the plane waves. The Brillouin zone integrations were sampled using a $4 \times 2 \times 2$ Monkhorst-Pack $k$-point mesh.

\section{Results and discussion}

\subsection{Phase purity, crystal structure, and site preference of dopants}

Fig. 1 presents the powder XRD patterns for the synthesized $\left(\mathrm{Ca}_{2.83-x} \mathrm{Eu}_{0.17} \mathrm{Bi}_{x}\right) \mathrm{ZrSi}_{2} \mathrm{O}_{9}(x=0-0.16)$ samples compared with the standard pattern (PDF no. 54-0710) for $\mathrm{Ca}_{3} \mathrm{ZrSi}_{2} \mathrm{O}_{9}$. All the diffraction peaks of these samples can be indexed to the $P 2_{1} / c$ space group (no. 14) of the monoclinic system, ${ }^{27}$ indicating that a single phase with high purity has been synthesized, and the doped $\mathrm{Bi}^{3+}$ and $\mathrm{Eu}^{3+}$ did not generate any impurity or induce significant changes in the host structure. The $\mathrm{Ca}_{3} \mathrm{ZrSi}_{2} \mathrm{O}_{9}$ compound can be regarded as being derived from the wellknown cuspidine $\mathrm{Ca}_{4} \mathrm{Si}_{2} \mathrm{O}_{7} \mathrm{~F}_{2}$ by substituting $\mathrm{Zr}-\mathrm{O}_{2}$ for $\mathrm{Ca}-\mathrm{F}_{2} \cdot{ }^{28}$ Thus, the crystal structure (shown in Fig. 2) of $\mathrm{Ca}_{3} \mathrm{ZrSi}_{2} \mathrm{O}_{9}$ is similar to $\mathrm{Ca}_{4} \mathrm{Si}_{2} \mathrm{O}_{7} \mathrm{~F}_{2}$, composed of $\left[\mathrm{SiO}_{4}\right]$ tetrahedrons, $\left[\mathrm{ZrO}_{6}\right]$ octahedrons, $\left[\mathrm{CaO}_{6}\right]$ octahedrons, and $\left[\mathrm{CaO}_{7}\right]$ decahedrons, forming a three dimensional network. There are three types of $\mathrm{Ca}^{2+}$ sites and one type of $\mathrm{Zr}^{4+}$ site, and they are available for $\mathrm{Eu}^{3+}$ and $\mathrm{Bi}^{3+}$ to occupy.

To identify the site preference, the formation energy $E_{\text {form }}$ was calculated according to the following equation: ${ }^{29,30}$

$$
E_{\text {form }}=E_{\mathrm{M}: \mathrm{CZSO}}-E_{\mathrm{CZSO}}+\mu_{\mathrm{Ca} \text { or Zr }}-\mu_{\mathrm{M}}
$$

where CZSO refers to $\mathrm{Ca}_{3} \mathrm{ZrSi}_{2} \mathrm{O}_{9}, \mathrm{M}$ represents metal $\mathrm{Eu}$ or $\mathrm{Bi}$, $E_{\mathrm{M}: \mathrm{CZsO}}$ and $E_{\mathrm{CZSO}}$ is the total energy of the metal-doped CZSO system and undoped CZSO, respectively, and $\mu$ is the total energy per atom of the bulk metal. According to this equation, the formation energies of $\mathrm{Eu}^{3+}$ and $\mathrm{Bi}^{3+}$ at possible cation sites were calculated and are shown in Fig. 3. As presented, both $\mathrm{Eu}^{3+}$ and $\mathrm{Bi}^{3+}$ exhibit much lower formation energy in the $\mathrm{Ca}^{2+}$ sites than in the $\mathrm{Zr}^{4+}$ site. The formation energy for $\mathrm{Eu}^{3+}$ and $\mathrm{Bi}^{3+}$ in

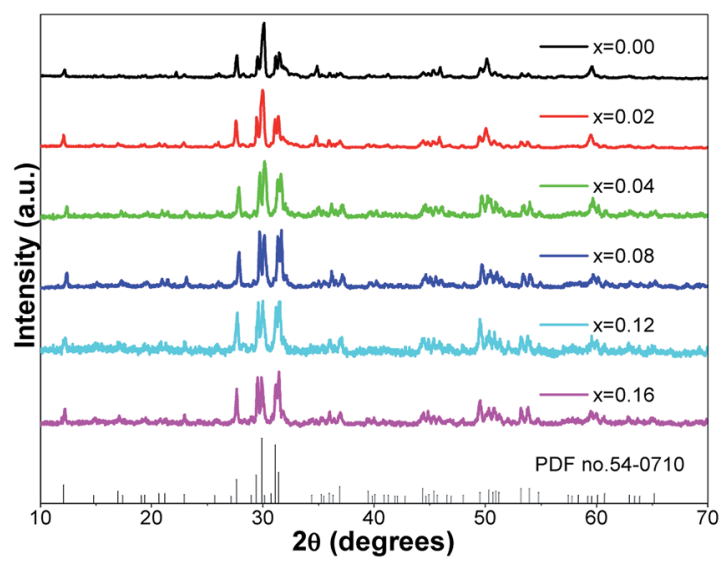

Fig. 1 Powder XRD patterns of the synthesized $\left(\mathrm{Ca}_{2.83-x} \mathrm{Eu}_{0.17} \mathrm{Bi}_{x}\right)$ $\mathrm{ZrSi}_{2} \mathrm{O}_{9}(x=0-0.16)$ samples, and the standard card (PDF no. 54-0710) of $\mathrm{Ca}_{3} \mathrm{ZrSi}_{2} \mathrm{O}_{9}$ is given for comparison. 


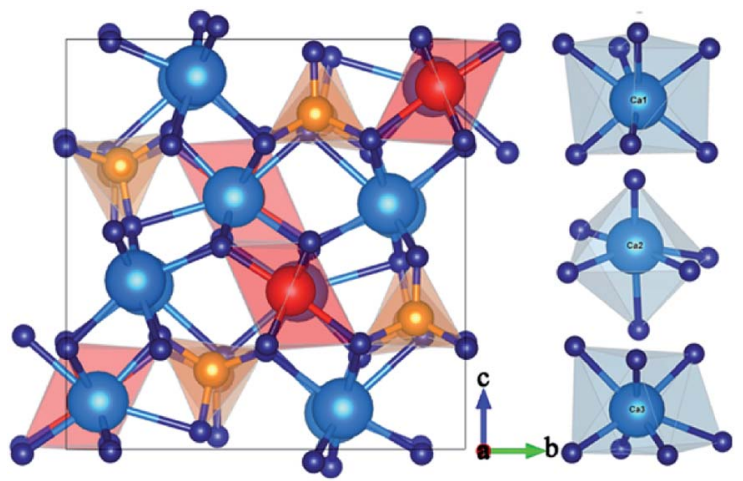

Fig. 2 Crystal structure of $\mathrm{Ca}_{3} \mathrm{ZrSi}_{2} \mathrm{O}_{9}$ views along the (100) direction; and three types of Ca sites, namely, Ca1, Ca2, and Ca3 with seven-, six-, and seven-coordinations, respectively.

three types of $\mathrm{Ca}^{2+}$ sites is very similar, but $\mathrm{Eu}^{3+}$ entering $\mathrm{Ca}_{(3)}$ and $\mathrm{Bi}^{3+}$ entering $\mathrm{Ca}_{(1)}$ provide slightly lower formation energy. These results indicate that $\mathrm{Eu}^{3+}$ and $\mathrm{Bi}^{3+}$ only occupy $\mathrm{Ca}^{2+}$ sites, but nearly have equal possibility to enter any type of $\mathrm{Ca}^{2+}$ site during the high temperature sintering process. The formation energy results also suggest that it is much more difficult to dope $\mathrm{Bi}^{3+}$ into the lattice than $\mathrm{Eu}^{3+}$, mainly due to its larger ionic radius and size mismatch effect.

\subsection{Electronic structure of $\mathrm{Bi}^{3+}$-doped and undoped $\mathrm{Ca}_{3} \mathrm{ZrSi}_{2} \mathrm{O}_{9}$}

Fig. 4a presents the total and partial density of states (DOSs) of the $\mathrm{Ca}_{3} \mathrm{ZrSi}_{2} \mathrm{O}_{9}$ host. As shown, the conduction band is mainly composed of $\mathrm{Ca} 3 \mathrm{~d}$ and $\mathrm{Zr} 4 \mathrm{~d}$ states, which show a hybridization character with $\mathrm{O} 2 \mathrm{p}$ and $\mathrm{Si} 3 \mathrm{p}$ states. The bottom of the conduction band is mainly determined by $\mathrm{Zr} 4 \mathrm{~d}$ states. The top of the valence band reflects the p electronic character, deriving from $\mathrm{O} 2 \mathrm{p}$ states. The valence bands at the lower energy are mainly attributed to $\mathrm{Si} 3 \mathrm{~s} / 3 \mathrm{p}$ and $\mathrm{O} 2 \mathrm{~s} / 2 \mathrm{p}$ states. The band gap is calculated to be $4.59 \mathrm{eV}$, corresponding to the optical absorption at $270 \mathrm{~nm}$ of $\mathrm{Zr}^{4+}-\mathrm{O}^{2-}$. This energy value is slightly

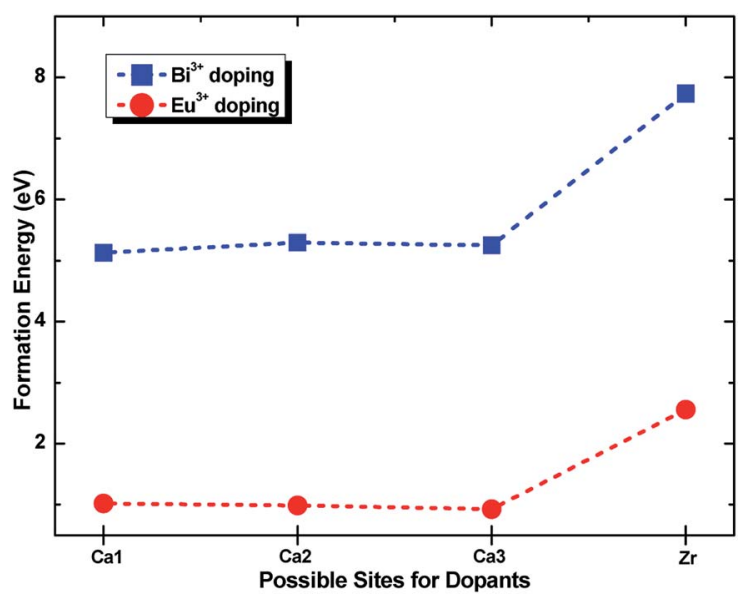

Fig. 3 Formation energy of $\mathrm{Eu}^{3+}$ and $\mathrm{Bi}^{3+}$ doping into $\mathrm{Zr}^{4+}$ and three types of $\mathrm{Ca}^{2+}$ sites in the $\mathrm{Ca}_{3} \mathrm{ZrSi}_{2} \mathrm{O}_{9}$ host. underestimated compared to the experimentally observed value of $255 \mathrm{~nm},{ }^{31}$ due to the drawback of the DFT method..$^{32}$

Fig. $4 \mathrm{~b}$ shows the total and partial density of states of $\mathrm{Bi}$ doped in the most possible $\mathrm{Ca}_{(1)}$ site. In this case, the bottom of the conduction band is mainly composed of $\mathrm{Zr} 4 \mathrm{~d}$ and $\mathrm{Bi} 6 \mathrm{p}$ states, and a strong hybridization between them can be observed. The p electronic character of the $\mathrm{O} 2 \mathrm{p}$ states remains at the top of the valence band. Additionally, the Bi $6 \mathrm{~s}$ states emerge at the band gap, slightly above the top of the valence band (by approximately $0.18 \mathrm{eV}$ ), presenting a strong hybridization with $\mathrm{O} 2 \mathrm{p}$ states. The band gap is reduced to $4.41 \mathrm{eV}$.

The total and partial density of states of Bi doped in the $\mathrm{Zr}$ site were also investigated and are presented in Fig. 4c. In this situation, the Bi $6 \mathrm{p}$ states are higher than the $\mathrm{Zr} 4 \mathrm{~d}$ states, and thus, the bottom of the conduction band is determined by the $\mathrm{Zr} 4 \mathrm{~d}$ states. The top of the valence band still presents the $\mathrm{p}$ electronic character of $\mathrm{O} 2 \mathrm{p}$ states, while the location of $\mathrm{Bi} 6 \mathrm{~s}$ is
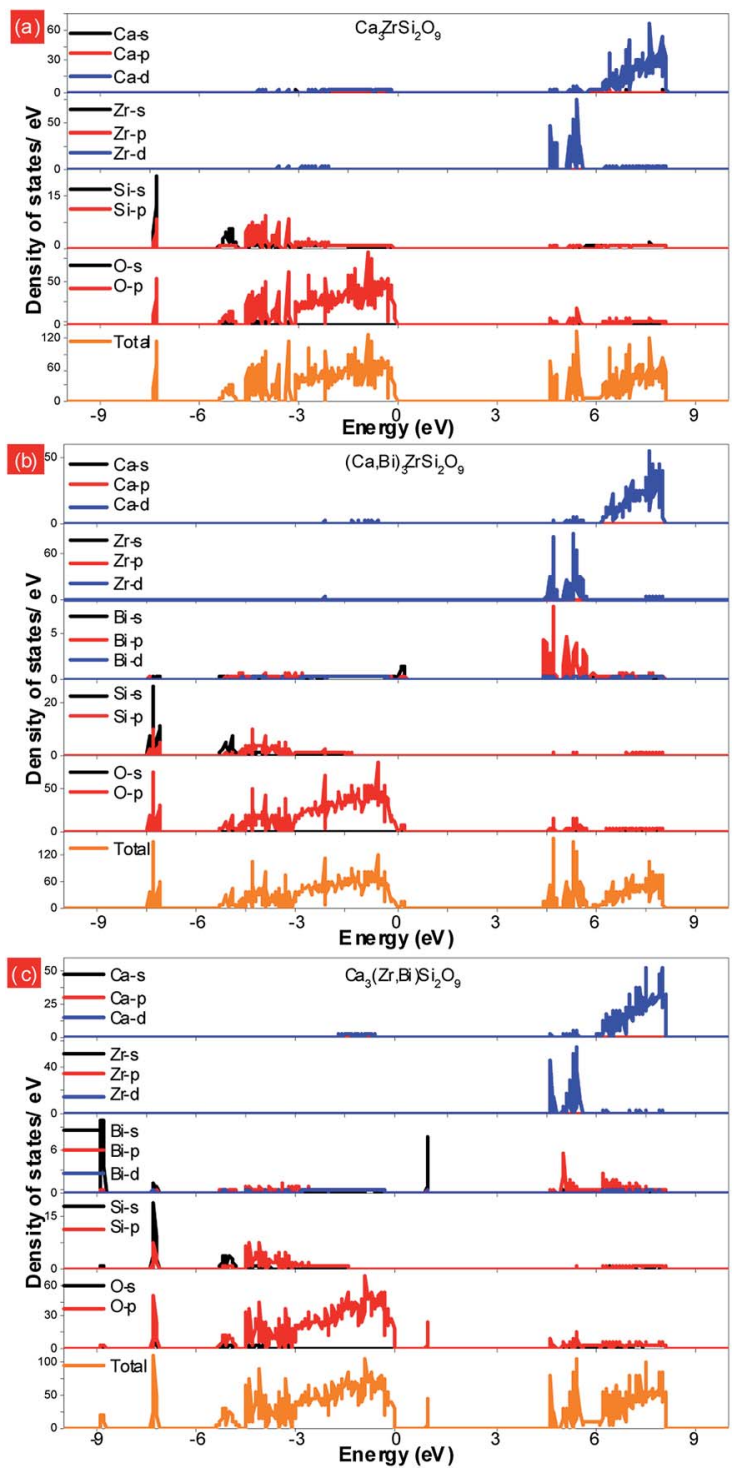

Fig. 4 Total and partial density of states of the (a) $\mathrm{Ca}_{3} \mathrm{ZrSi}_{2} \mathrm{O}_{9}$ host; (b) $\mathrm{Bi}^{3+}$ doping into the $\mathrm{Ca}_{(1)}$ site; and (c) $\mathrm{Bi}^{3+}$ doping into the $\mathrm{Zr}^{4+}$ site. 
significantly higher than that with $\mathrm{Bi}$ doping at the $\mathrm{Ca}_{(1)}$ site. Also, a strong hybridization between the $\mathrm{Bi} 6 \mathrm{~s}$ and $\mathrm{O} 2 \mathrm{p}$ states can be detected. The band gap is not influenced by the doped $\mathrm{Bi}$ and remained at $4.59 \mathrm{eV}$.

\subsection{Photoluminescence properties of $\mathrm{Ca}_{3} \mathrm{ZrSi}_{2} \mathrm{O}_{9}: \mathrm{Eu}^{3+}, x \mathrm{Bi}^{3+}$}

The photoluminescence emission (PL) spectra of samples $\left(\mathrm{Ca}_{2.83-x} \mathrm{Eu}_{0.17} \mathrm{Bi}_{x}\right) \mathrm{ZrSi}_{2} \mathrm{O}_{9}(x=0-0.16)$ excited by $300 \mathrm{~nm} \mathrm{UV}$ light are presented in Fig. 5. As shown, the spectrum exhibits typical characteristics of $\mathrm{Eu}^{3+}$, with several sharp emission peaks located at $579 \mathrm{~nm}, 586 / 595 \mathrm{~nm}, 610 / 622 / 626 / 630 \mathrm{~nm}, 648$ / $654 \mathrm{~nm}$, and 704/707/709/712 $\mathrm{nm}$ corresponding to the transitions of ${ }^{5} \mathrm{D}_{0} \rightarrow{ }^{7} \mathrm{~F}_{J}(J=0-4),{ }^{33,34}$ respectively. The emission intensity gradually increases and then decreases with the increasing concentration of $\mathrm{Bi}^{3+}$ doping. The optimized $\mathrm{Bi}^{3+}$ concentration is $x=0.08$, with an inner quantum yield of $72.9 \%$ and external quantum yield of $59.7 \%$ under $300 \mathrm{~nm}$ excitation, while the sample without $\mathrm{Bi}^{3+}$ doping has an inner quantum yield of $34.6 \%$ and external quantum yield of $27.3 \%$ under the same measured conditions. This emission enhancement is mainly ascribed to the sensitization provided by $\mathrm{Bi}^{3+}$ because $\mathrm{Bi}^{3+}$ can absorb energy through ${ }^{1} \mathrm{~S}_{0} \rightarrow{ }^{3} \mathrm{P}_{1}$ and ${ }^{1} \mathrm{~S}_{0} \rightarrow{ }^{1} \mathrm{P}_{1}$ transitions and transfer its energy to $\mathrm{Eu}^{3+}$, improving the absorbance of this phosphor. However, when the $\mathrm{Bi}^{3+}$ doping concentration exceeds $x=0.08$, more defects may form due to nonequivalence substitution, resulting in a slight decrease in emission intensity. ${ }^{35}$

The normalized photoluminescence excitation spectra of $\left(\mathrm{Ca}_{2.83-x} \mathrm{Eu}_{0.17} \mathrm{Bi}_{x}\right) \mathrm{ZrSi}_{2} \mathrm{O}_{9}(x=0$ and 0.08$)$ monitored at $610 \mathrm{~nm}$ are compared and shown in Fig. 6. It can be observed that the excitation peaks ascribing to $\mathrm{f}-\mathrm{f}$ transitions of $\mathrm{Eu}^{3+}$ are in good agreement at each wavelength, while the charge transfer band (CTB) presents a redshift of approximately $10 \mathrm{~nm}$ (approximately $0.14 \mathrm{eV}$ ) when $\mathrm{Bi}^{3+}$ was introduced in this phosphor, which indicates that the $4 \mathrm{f}$ energy levels are not influenced by

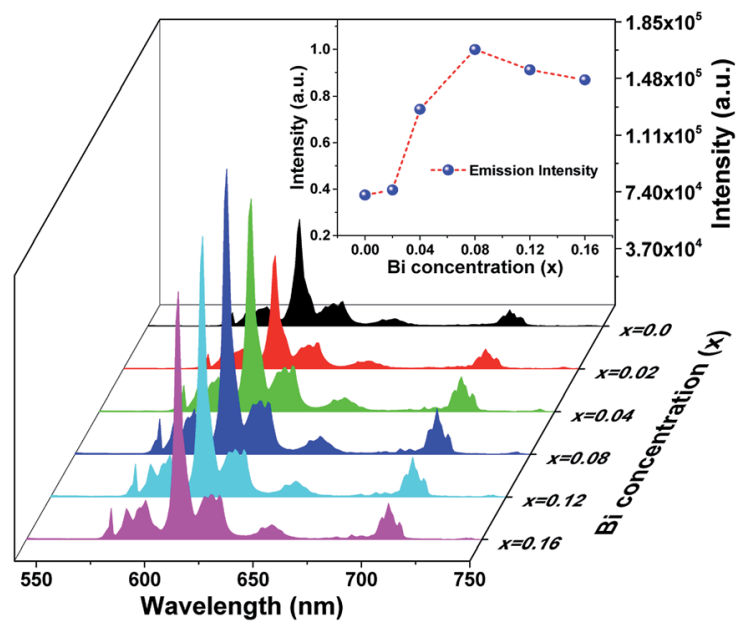

Fig. 5 The photoluminescence emission spectra of samples $\left(\mathrm{Ca}_{2.83-x} \mathrm{Eu}_{0.17} \mathrm{Bi}_{x}\right) \mathrm{ZrSi}_{2} \mathrm{O}_{9}(x=0-0.16)$ excited by $300 \mathrm{~nm}$ UV light. The emission intensity of the dominant peak $(610 \mathrm{~nm})$ as a function of $\mathrm{Bi}^{3+}$ concentration was inserted.

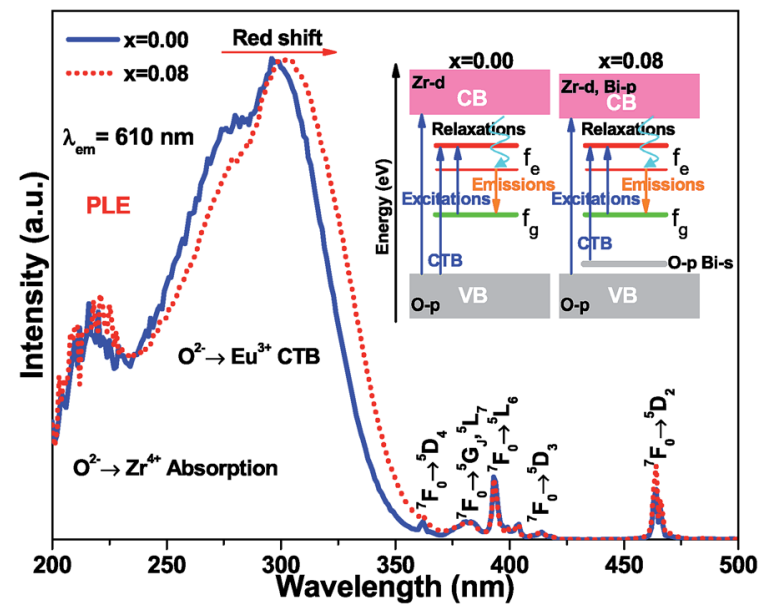

Fig. 6 The normalized photoluminescence excitation spectra of $\left(\mathrm{Ca}_{2.83-x} \mathrm{Eu}_{0.17} \mathrm{Bi}_{x}\right) \mathrm{ZrSi}_{2} \mathrm{O}_{9}(x=0$ and 0.08$)$ monitored at $610 \mathrm{~nm}$. A sketch of involved energy level variations was inserted.

$\mathrm{Bi}^{3+}$ doping, but the band gap and $\mathrm{Eu}^{3+}-\mathrm{O}^{2-}$ interactions may have been affected. ${ }^{\mathbf{1 6 , 3 6}}$ This redshift is mainly ascribed to the existence of a hybrid level constituted by $\mathrm{O} 2 \mathrm{p}$ and $\mathrm{Bi}$ 6s states above the valence band, which decrease the energy between the $\mathrm{O} 2 \mathrm{p}$ and Eu $4 \mathrm{f}$ states. The energy difference (approximately 0.14 $\mathrm{eV}$ ) corresponding to the redshift in CTB is very close to the energy separation (approximately $0.18 \mathrm{eV}$ ) between the above mentioned hybrid level and the top of the valence band obtained by DFT calculation (shown in Fig. 4b), which further confirms that $\mathrm{Bi}^{3+}$ prefers to enter $\mathrm{Ca}^{2+}$ sites, especially the $\mathrm{Ca}_{(1)}$ site. Additionally, we can also find the redshift of the $\mathrm{Zr}^{4+}-\mathrm{O}^{2-}$ absorption band at a high energy, and this shift should be ascribed to the lowering of the conduction band induced by $\mathrm{Bi}^{3+}$ doping. The involved energy level variations are shown in the sketch inserted in Fig. 6.

Fig. 7 illustrates the normalized fluorescence decay curves of $\left(\mathrm{Ca}_{2.83-x} \mathrm{Eu}_{0.17} \mathrm{Bi}_{x}\right) \mathrm{ZrSi}_{2} \mathrm{O}_{9}(x=0-0.16)$ excited by $300 \mathrm{~nm} \mathrm{UV}$

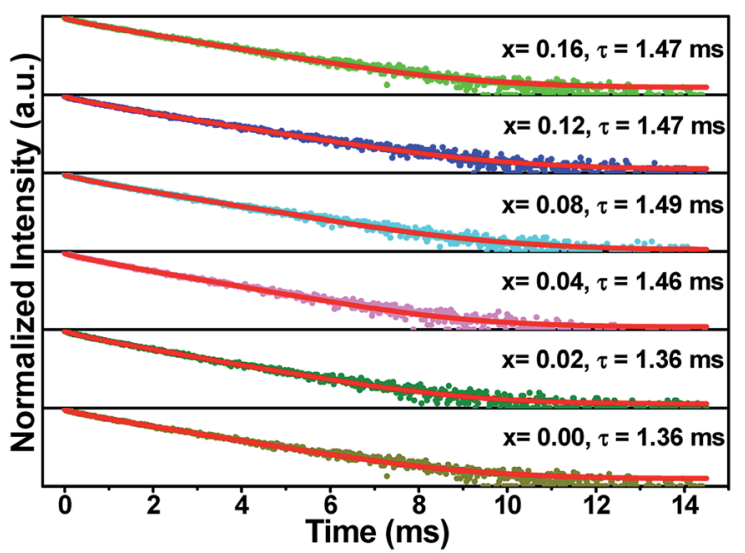

Fig. 7 The normalized fluorescence decay curves of $\left(\mathrm{Ca}_{2.83-x} \mathrm{Eu}_{0.17^{-}}\right.$ $\left.\mathrm{Bi}_{x}\right) \mathrm{ZrSi}_{2} \mathrm{O}_{9}(x=0-0.16)$ excited by $300 \mathrm{~nm}$ UV light and monitored at $610 \mathrm{~nm}$, and lifetimes that were calculated by fitting two exponential functions. 
light and monitored at $610 \mathrm{~nm}$. These decay curves are unable to be fitted by a single exponential function, but can be well fitted by a two-exponential function. Generally, $\mathrm{Eu}^{3+}$ occupies three types of $\mathrm{Ca}^{2+}$ sites, and it is more reasonable to fit the decay curves by a three-exponential function than a twoexponential function. However, due to the similarity between the coordination numbers and symmetry of the $\mathrm{Ca}_{(1)}$ site and the $\mathrm{Ca}_{(3)}$ site, $\mathrm{Eu}^{3+}$ enters either the $\mathrm{Ca}_{(1)}$ site or $\mathrm{Ca}_{(3)}$ site, and the luminescent properties are quite similar. Thus, it is reasonable to fit the decay curves by a two-exponential function. In this method, the decay times were determined to be $1.36 \mathrm{~ms}$, $1.36 \mathrm{~ms}, 1.46 \mathrm{~ms}, 1.49 \mathrm{~ms}, 1.47 \mathrm{~ms}$, and $1.47 \mathrm{~ms}$ for $\left(\mathrm{Ca}_{2.83-x^{-}}\right.$ $\left.\mathrm{Eu}_{0.17} \mathrm{Bi}_{x}\right) \mathrm{ZrSi}_{2} \mathrm{O}_{9}(x=0-0.16)$ phosphors with increasing $\mathrm{Bi}^{3+}$ concentration. In terms of the values of decay times, it is difficult to find obvious regularity, but a trend is exhibited of first an increase and then a decrease. The reason for the increased decay time is mainly due to the energy transfer from $\mathrm{Bi}^{3+}$ to $\mathrm{Eu}^{3+}$, while a further increase in $\mathrm{Bi}^{3+}$ concentration will create more defects that trap the excited electrons, reducing the decay times. $^{37,38}$

The thermal quenching property, namely emission loss with increasing temperature, is one of the key application criteria for practical phosphors. ${ }^{39}$ The temperature-dependent normalized inner quantum yield of $\left(\mathrm{Ca}_{2.83-x} \mathrm{Eu}_{0.17} \mathrm{Bi}_{x}\right) \mathrm{ZrSi}_{2} \mathrm{O}_{9}(x=0$ and 0.08) phosphors under $300 \mathrm{~nm}$ UV excitation are presented in Fig. 8a. It can be detected that the $\mathrm{Bi}^{3+}$-doped phosphor has better thermal stability than that without $\mathrm{Bi}^{3+}$ doping at any point in the measured temperature range $\left(25-250{ }^{\circ} \mathrm{C}\right)$. We observed that the quantum yield as well as emission intensity (shown as Fig. 8b) first increases up to a temperature of $50{ }^{\circ} \mathrm{C}$ and then decreases in the $\left(\mathrm{Ca}_{2.83-x} \mathrm{Eu}_{0.17} \mathrm{Bi}_{x}\right) \mathrm{ZrSi}_{2} \mathrm{O}_{9}(x=0.08)$ phosphor. The photoluminescence (PL) intensity increase is generally ascribed to the formation of defect levels in the phosphor, which can capture electrons and then release them with increasing temperature, causing the increase of the PL intensity. ${ }^{40,41}$ Because of the effect of defects in increasing the

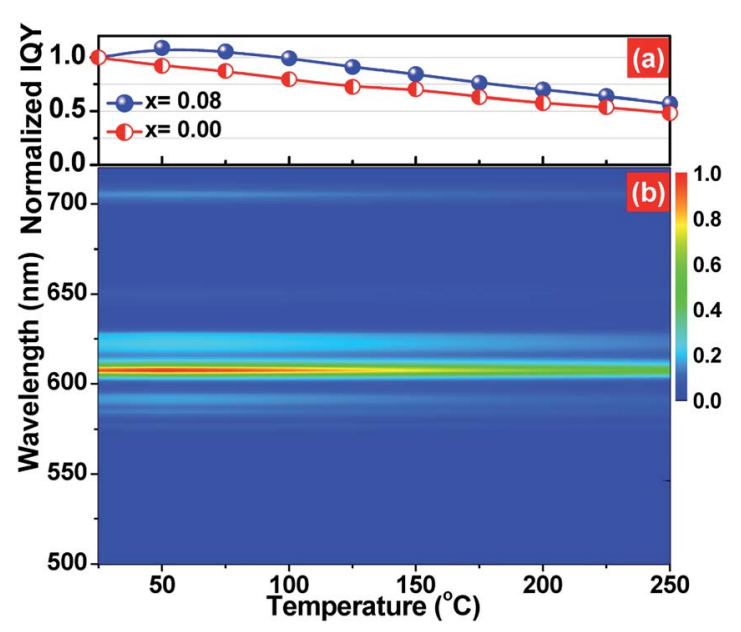

Fig. 8 (a) The temperature-dependent normalized inner quantum yield of $\left(\mathrm{Ca}_{2.83-x} \mathrm{Eu}_{0.17} \mathrm{Bi}_{x}\right) \mathrm{ZrSi}_{2} \mathrm{O}_{9}(x=0$ and 0.08$)$ phosphors under $300 \mathrm{~nm}$ excitation and (b) the temperature-dependent emission spectrum of the $\left(\mathrm{Ca}_{2.83-x} \mathrm{Eu}_{0.17} \mathrm{Bi}_{x}\right) \mathrm{ZrSi}_{2} \mathrm{O}_{9}(x=0.08)$ phosphor.

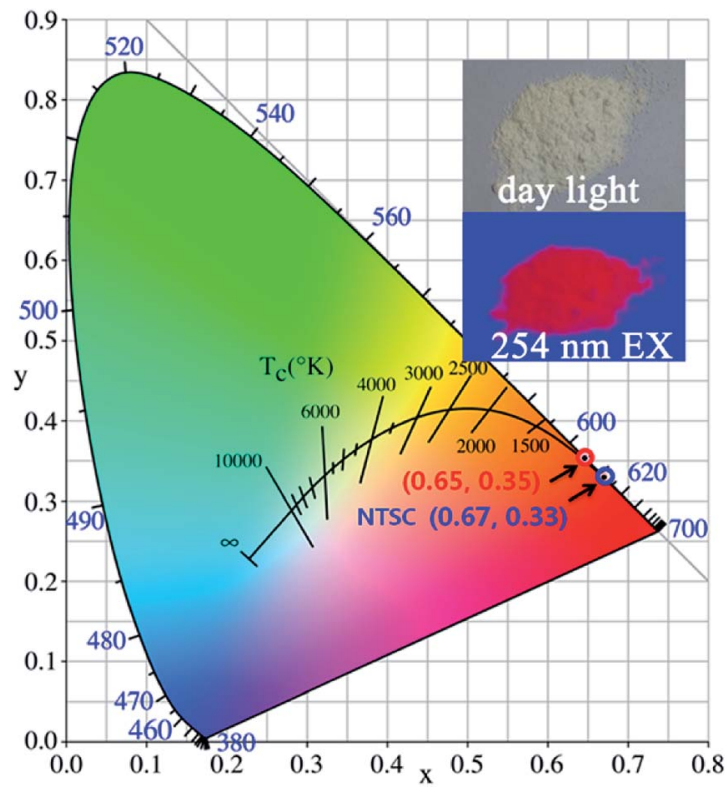

Fig. $9 \mathrm{CIE}$ coordinates of $\left(\mathrm{Ca}_{2.83-x} \mathrm{Eu}_{0.17} \mathrm{Bi}_{x}\right) \mathrm{ZrSi}_{2} \mathrm{O}_{9} \quad(x=0-0.16)$ phosphors under excitation at $300 \mathrm{~nm}$. A digital photo of the $\left(\mathrm{Ca}_{2.83-x} \mathrm{Eu}_{0.17} \mathrm{Bi}_{x}\right) \mathrm{ZrSi}_{2} \mathrm{O}_{9}(x=0.08)$ phosphor under daylight and a $254 \mathrm{~nm}$ UV lamp is shown at the upper right.

thermal stability, this $\mathrm{Bi}^{3+}$-doped phosphor can remain at $84.2 \%$ of the initial quantum yield (at room temperature) when the temperature was increased up to $150{ }^{\circ} \mathrm{C}$. The yield is better than that of $\mathrm{Y}_{2} \mathrm{O}_{3}: \mathrm{Eu}^{3+}$ (approximately 81\%) and comparable to commercial $\mathrm{Sr}_{2} \mathrm{Si}_{5} \mathrm{~N}_{8}: \mathrm{Eu}^{2+}$ (approximately 85\%), ${ }^{\mathbf{4 2 - 4 4}}$ and is much higher than that without $\mathrm{Bi}^{3+}$ doping (70.1\%). This thermal stability enhancement is different from the traditional reduction of cross relaxation or thermal ionization, ${ }^{\mathbf{4 5 , 4 6}}$ mainly ascribing to the appropriate amount of defects created by $\mathrm{Bi}^{3+}$ doping.

Furthermore, the CIE chromaticity coordinates for $\left(\mathrm{Ca}_{2.83-x} \mathrm{Eu}_{0.17} \mathrm{Bi}_{x}\right) \mathrm{ZrSi}_{2} \mathrm{O}_{9}(x=0-0.16)$ excited at $300 \mathrm{~nm}$ were calculated, but the values were the same, which reflects the fact that $\mathrm{Bi}^{3+}$ doping did not change the occupancy of $\mathrm{Eu}^{3+}$ at any type of $\mathrm{Ca}^{2+}$ site. The CIE chromaticity coordinates were determined to be $(0.65,0.35)$ (depicted in Fig. 9), which are close to those of standard red $(0.67,0.33)$ given by the NTSC (National Television Standards Committee). ${ }^{47}$ Additionally, a digital photo of the $\left(\mathrm{Ca}_{2.83-x} \mathrm{Eu}_{0.17} \mathrm{Bi}_{x}\right) \mathrm{ZrSi}_{2} \mathrm{O}_{9}(x=0.08)$ phosphor under daylight and a $254 \mathrm{~nm}$ UV lamp is shown in the inset of Fig. 9, demonstrating an intense red light emission from this phosphor under UV light excitation. With further synthetic process optimization, the luminescent properties of this phosphor are expected to be further promoted.

\section{Conclusions}

We have synthesized $\left(\mathrm{Ca}_{2.83-x} \mathrm{Eu}_{0.17} \mathrm{Bi}_{x}\right) \mathrm{ZrSi}_{2} \mathrm{O}_{9}(x=0-0.16)$ phosphors by a conventional high-temperature solid-state reaction method using inexpensive raw materials. The DFT calculation demonstrates that the doped $\mathrm{Bi}^{3+}$ and $\mathrm{Eu}^{3+}$ prefer to 
occupy $\mathrm{Ca}^{2+}$ sites. The redshift of the charge transfer band (CTB) induced by $\mathrm{Bi}^{3+}$ doping of the $\mathrm{Ca}_{3} \mathrm{ZrSi}_{2} \mathrm{O}_{9}: \mathrm{Eu}^{3+}$ phosphor should be ascribed to the existence of a hybrid level constituted by the $\mathrm{O} 2 \mathrm{p}$ and $\mathrm{Bi}$ 6s states located above the valence band. The inner quantum yield of the optimized sample with $x=0.08$ was promoted to $72.9 \%$, due to the efficient sensitizing of $\mathrm{Eu}^{3+}$ with $\mathrm{Bi}^{3+}$. The formation of the appropriate amount of defects created by nonequivalence substitution, namely $\mathrm{Bi}^{3+}$ substituting $\mathrm{Ca}^{2+}$, is beneficial for increasing the thermal stability of $\mathrm{Eu}^{3+}$ in this phosphor. The optimized sample can remain at $84.2 \%$ of the initial quantum yield (at room temperature) when the temperature was raised to $150{ }^{\circ} \mathrm{C}$. These parameters indicate that the $\mathrm{Bi}^{3+}$-doped $\mathrm{Ca}_{3} \mathrm{ZrSi}_{2} \mathrm{O}_{9}: \mathrm{Eu}^{3+}$ phosphor exhibits a particularly high quantum yield and excellent thermal stability, and can serve as red-emitting phosphors for future deep UV LEDs.

\section{Conflicts of interest}

There are no conflicts of interest to declare.

\section{Acknowledgements}

This present work was financially supported by the National Basic Research Program of China (2014CB643801); the National Natural Science Foundation of China (No. 51702057); China Postdoctoral Science Foundation (2017M622627); Major Program for Cooperative Innovation of Production, Education \& Research of Guangzhou City (201704030106; 201604016029); and Science and Technology Planning Projects of Guangdong Province of China (2014B050505020; 2016201604030035).

\section{Notes and references}

1 S. Pimputkar, J. S. Speck, S. P. DenBaars and S. Nakamura, Nat. Photonics, 2009, 3, 180.

2 X. Huang, Nat. Photonics, 2014, 8, 748.

3 E. F. Schubert and J. K. Kim, Science, 2005, 308, 1274.

4 P. Pust, V. Weiler, C. Hecht, A. Tücks, A. S. Wochnik, A. K. Henß, D. Wiechert, C. Scheu, P. J. Schmidt and W. Schnick, Nat. Mater., 2014, 13, 891.

5 C. C. Lin and R. S. Liu, J. Phys. Chem. Lett., 2011, 2, 1268.

6 C. Cajochen, S. Frey, D. Anders, J. Späti, M. Bues, A. Pross, R. Mager, A. Wirz-Justice and O. Stefani, J. Appl. Physiol., 2011, 110, 1432.

7 A. Haim and A. E. Zubidat, Chronobiol. Int., 2015, 32, 725.

8 M. H. Fang, C. Ni, X. Zhang, Y. T. Tsai, S. Mahlik, A. Lazarowska, M. Grinberg, H. S. Sheu, J. F. Lee, B. M. Cheng and R. S. Liu, ACS Appl. Mater. Interfaces, 2016, 8, 30677.

9 C. Yan, Z. Liu, W. Zhuang, R. Liu, X. Xing, Y. Liu, G. Chen, Y. Li and X. Ma, Inorg. Chem., 2017, 56, 11087.

10 Y. Muramoto, M. Kimura and S. Nouda, Semicond. Sci. Technol., 2014, 29, 084004.

11 L. Chen, K. J. Chen, C. C. Lin, C. I. Chu, S. F. Hu, M. H. Lee and R. S. Liu, J. Comb. Chem., 2010, 12, 587.
12 S. W. Kim, Y. Zuo, T. Masui and N. Imanaka, ECS Solid State Lett., 2013, 2, R34.

13 Y. Zuo, S. W. Kim, T. Masui and N. Imanaka, ECS J. Solid State Sci. Technol., 2014, 3, R79.

14 G. Blasse and A. Bril, J. Chem. Phys., 1968, 48, 217.

15 H. Zhou, M. Jiang and Y. Jin, RSC Adv., 2014, 4, 45786.

16 F. Kang, H. Zhang, L. Wondraczek, X. Yang, Y. Zhang, D. Y. Lei and M. Peng, Chem. Mater., 2016, 28, 2692.

17 L. Li, Y. Pan, Z. Chen, S. Huang and M. Wu, RSC Adv., 2017, 7, 14868.

18 X. Yu, L. Zhang, X. Xu, T. Wang, H. Yu, T. Jiang, Q. Jiao, Z. Yang, D. Zhou and J. Qiu, J. Lumin., 2014, 145, 114.

19 F. Kang, Y. Zhang and M. Peng, Inorg. Chem., 2015, 54, 1462. 20 Q. Su, C. Barthou, J. P. Denis, F. Pelle and B. Blanzat, J. Lumin., 1983, 28, 1.

21 M. Darbandi, W. Hoheisel and T. Nann, Nanotechnology, 2006, 17, 4168.

22 T. S. Chan, C. C. Kang, R. S. Liu, L. Chen, X. N. Liu, J. J. Ding, J. Bao and C. Gao, J. Comb. Chem., 2007, 9, 343.

23 P. Perdew, K. Burke and M. Ernzerhof, Phys. Rev. Lett., 1996, $77,3865$.

24 G. Kresse and J. Furthmüller, Phys. Rev. B: Condens. Matter Mater. Phys., 1996, 54, 11169.

25 G. Kresse and D. Joubert, Phys. Rev. B: Condens. Matter Mater. Phys., 1999, 59, 1758.

26 P. E. Blöchl, Phys. Rev. B: Condens. Matter Mater. Phys., 1994, 50, 17953.

27 J. R. Plaister, J. Jansen, R. A. G. de Graaff and D. J. W. IJdo, J. Solid State Chem., 1995, 115, 464.

28 E. Burzo, Sorosilicates, Springer Berlin Heidelberg, 2005, vol. 2712, p. 142.

29 S. Jang, J. Im, B. K. Bang, C. H. Kim, H. Chang and K. j. Kong, RSC Adv., 2015, 5, 39319.

30 Z. Wang, B. Shen, F. Dong, S. Wang and W. S. Su, Phys. Chem. Chem. Phys., 2015, 17, 15065.

31 G. Blassea, G. Bernardi, D. J. W. Ijdob and J. R. Plaisier, J. Alloys Compd., 1995, 217, 29.

32 J. Wen, L. Ning, C. K. Duan, Y. Chen, Y. Zhang and M. Yin, J. Phys. Chem. C, 2012, 116, 20513.

33 Q. Zhang, X. Wang, X. Ding and Y. Wang, Inorg. Chem., 2017, 56, 6990 .

34 J. Huo, L. Dong, W. Lü, B. Shao and H. You, Phys. Chem. Chem. Phys., 2017, 19, 17314.

35 J. Zhong, W. Zhuang, X. Xing, L. Wang, Y. Li, Y. Zheng, R. Liu, Y. Liu and Y. Hu, J. Alloys Compd., 2016, 674, 93.

36 X. T. Wei, J. Wen, S. Li, S. Huang, J. Cheng, Y. H. Chen, C. K. Duan and M. Yin, Appl. Phys. Lett., 2014, 104, 181904. 37 K. Zhang, W. Hu, Y. Wu and H. Liu, Phys. B, 2008, 403, 1678. 38 F. Du, W. Zhuang, R. Liu, Y. Liu, J. Zhong, P. Gao, X. Zhang, W. Gao and L. Shao, RSC Adv., 2017, 7, 1075.

39 J. Ueda, P. Dorenbos, A. J. J. Bos, A. Meijerink and S. Tanabe, J. Phys. Chem. C, 2015, 119, 25003.

40 Y. H. Kim, P. Arunkumar, B. Y. Kim, S. Unithrattil, E. Kim, S. H. Moon, J. Y. Hyun, K. H. Kim, D. Lee, J. S. Lee and W. B. Im, Nat. Mater., 2017, 16, 543.

41 M. Zhang, Z. Xia and Q. Liu, J. Mater. Chem. C, 2017, 5, 7489. 
42 X. Wang, Z. Zhao, Q. Wu, Y. Li and Y. Wang, Inorg. Chem., 2016, 55, 11072.

43 C. W. Yeh, W. T. Chen, R. S. Liu, S. F. Hu, H. S. Sheu, J. M. Chen and H. T. Hintzen, J. Am. Chem. Soc., 2012, 134, 14108.

44 L. Chen, R. H. Liu, W. D. Zhuang, Y. H. Liu, Y. S. Hu, X. F. Zhou, W. Gao and X. L. Ma, CrystEngComm, 2015, 17, 3687.
45 J. Zhong, W. Zhuang, X. Xing, R. Liu, Y. Li, Y. Liu and Y. Hu, J. Phys. Chem. C, 2015, 119, 5562.

46 X. Qin, X. Liu, W. Huang, M. Bettinelli and X. Liu, Chem. Rev., 2017, 117, 4488.

47 A. R. Smith, ACM SIGGRAPH Computer Graphics, 1978, 12, 12. 